\title{
Low Grade Lung Neuroendocrine Neoplasm
}

National Cancer Institute

\section{Source}

National Cancer Institute. Low Grade Lung Neuroendocrine Neoplasm. NCI Thesaurus.

Code C45567.

A low grade malignant neoplasm with neuroendocrine differentiation that arises from the lung. This category includes typical carcinoid tumor. 